\title{
Numerical Analysis of Flow Behavior in Vortex Tube for Different Gases
}

\author{
Kiran Dattatraya Devade ${ }^{1}$, Ashok T. Pise ${ }^{2} \&$ Atul R. Urade ${ }^{3}$ \\ ${ }^{1}$ Indira College of Engineering and Management, India \\ ${ }^{2}$ Government College of Engineering, Karad, Maharashtra, India \\ ${ }^{3}$ G. H. Raisoni College of Engineering, Wagholi, Pune, India \\ Correspondence: Kiran Dattatraya Devade, Indira College of Engineering and Management, India. E-mail: \\ kiran.devade@gmail.com
}

Received: June 16, 2017

Accepted: September 25, 2017

Online Published: November 29, 2017

doi:10.5539/mer.v7n2p18

URL: https://doi.org/10.5539/mer.v7n2p18

\begin{abstract}
The vortex tube is an energy separation device that separates compressed gas stream into a low and a high temperature stream. Present work reports the flow behavior inside the vortex tube for different commonly used fluids with varied properties like Air, $\mathrm{He}, \mathrm{N}_{2}, \mathrm{CO}_{2}$ and $\mathrm{NH}_{3}$. Flow behavior investigation for three-dimensional short straight-diverging vortex tube is done with CFD code (ANSYS 16.0). Different turbulent models, standard k- $\varepsilon$, Realizable k- $\varepsilon$ and RNG k- $\varepsilon$ are tested. Realizable k- $\varepsilon$ model was then used for analysis. Flow behavior of gases with varied multi-atomic number is analyzed and compared with literature. The effect on temperature for $\mathrm{N}_{2}$ is found to be better, followed by $\mathrm{He}, \mathrm{CO}_{2}$, Air and $\mathrm{NH}_{3}$. Energy separation for $\mathrm{N}_{2}$ is $46 \%$ higher than all other gases. Energy separation and flow behavior inside vortex tube is analyzed and compared with literature.
\end{abstract}

Keywords: vortex tube, energy separation, total temperature, total pressure, radial distribution, gases

\section{NOMENCLATURE}

A Area

a Redlich Kwong constant

b Redlich Kwong constant

C Constant

c specific heat capacity

d diameter

D tube diameter

E Total energy

$f \quad$ Frequency

$\mathrm{F} \quad$ Force

G generation

h specific enthalpy

i internal energy per unit mass

$\mathrm{k} \quad$ turbulent kinetic energy

L length of the RHVT

m Mass

n outward surface vector

$\mathrm{N} \quad$ Number of nodes

P Pressure $\mathrm{m}^{2}$

$\mathrm{Jkg}^{-1} \mathrm{~K}^{-1}$
$\mathrm{~m}$
$\mathrm{~m}$
$\mathrm{~J}$
$\mathrm{~Hz}$
$\mathrm{~N}$
$\mathrm{JKg}^{-1}$
$\mathrm{JKg}^{-1}$
$\mathrm{Msec}^{-1}$
$\mathrm{M}^{-1}$
$\mathrm{Kg}$

$\mathrm{Nm}^{-2}$




$\begin{array}{cl}\text { Q } & \text { heat energy } \\ \mathrm{R} & \text { Universal gas constant } \\ s & \text { Entropy } \\ \mathrm{T} & \text { temperature } \\ \mathrm{t} & \text { Time }\end{array}$

J

$\mathrm{Jmol}^{-1} \cdot \mathrm{K}^{-1}$

$\mathrm{Jkg}^{-1} \cdot \mathrm{K}^{-1}$

K

S

$\mathrm{m}^{2} \mathrm{sec}^{-1}$

\section{Greek Symbols}

r, $\Theta \quad$ Polar coordinates

v kinematic viscosity

$\alpha \quad$ Valve angle

$\beta \quad$ Coefficient of thermal expansion

$\gamma \quad$ ratio of specific heat capacities

$\Delta \quad$ Delta

$\varepsilon \quad$ rate of turbulent dissipation per unit mass

$\mathrm{m}^{2} \mathrm{sec}^{-3}$

$\mu \quad$ Viscosity

$\mathrm{Kgm}^{-1} \cdot \mathrm{sec}^{-1}$

$\mu \quad$ gas fraction

$\mu \quad$ turbulent viscosity

$\rho \quad$ Density

$\tau \quad$ shear stress

$\Omega \quad$ Swirl number

$\Gamma \quad$ Diffusivity

$\nabla \quad$ Divergence

$\beta \quad$ Cold diameter ratio

$\eta \quad$ Efficiency

\section{Subscripts}

$\begin{array}{ll}\text { b } & \text { Buoyancy } \\ \text { e } & \text { cold outlet } \\ \text { eff } & \text { Entry } \\ \text { ex } & \text { Exfective } \\ f & \text { Face } \\ \text { h } & \text { hot outlet } \\ \text { i,j } & \text { tensor notation } \\ \text { in } & \text { inlet } \\ \text { mol } & \text { Mole } \\ \text { o } & \text { Total } \\ \mathrm{p} & \text { constant pressure } \\ \mathrm{s} & \text { Static } \\ s & \text { Source } \\ \mathrm{t} & \text { Turbulent } \\ \mathrm{v} & \text { constant volume }\end{array}$




\section{Introduction}

Vortex tube produces hot and cold streams of air from tangentially supplied compressed air. It is one of the nonconventional refrigeration devices. Ranque G.J. (Ranque, 1933) invented the vortex tube. The tube being inefficient it was unnoticed until Hilsch (Hilsch, 1947) started working on enhancing efficiency of the tube. After invention, Ranque's explanation to the vortex effect was criticised. (Westley, 1954; Brun, 1933) The investigations took momentum following Hilsch work. The tube hence is widely known as RHVT (Ranque-Hilsch Vortex Tube). The device is simple in construction and consists of inlet nozzle/s, vortex chamber, vortex generator, hot side with valve, cold side containing orifice. The mechanism of the working of the vortex tube is as follows. Compressed air enters tangentially inside the tube through the nozzle as shown in Figure 2. At entry, the air expands and attains high velocity. Air travels in a spiral like motion along the periphery of the tube. The valve at the hot end of the tube restricts this swirling flow and the pressure near the exit valve increases slightly. With the valve closure, the flow becomes stagnant and kinetic energy of the flow converts into heat energy. On the axis, this stagnant flow locates stagnation point, which contributes to the energy separation by virtue of its position.

The flow of air reverses from slightly high-pressure region created at the hot end of the low-pressure region at entry. The reversed stream flows through the core of the tube. Peripheral high velocity flow surrounds or encompasses the reversed flow stream. The peripheral stream makes the central layer to rotate, thus central layer gains rotation at the expense of heat. This causes heat transfer to take place between reversed core stream and peripheral stream. Therefore, air stream passing through the core, is cooled below the inlet temperature of the air in the vortex tube, while the air stream in forward direction is heated. The cold and hot stream emerging out simultaneously has derived attention of many researchers. This separation of streams is also known as thermal separation, energy separation, or vortex effect. This is one of the explanations of vortex tube mechanism. The literature review shows the efforts made in the similar direction.

Since invention, many researchers have tried to explore the energy separation phenomenon by experimental and numerical approach. Aljuwayhel et al. used (Aljuwayhel, Nellis, \& Klein, 2005) a 2-D axisymmetric model with RNG $\mathrm{k}-\varepsilon$ turbulence model. The solution was obtained at $\mathrm{CMF}=0.3$, the reason of energy separation was attributed to viscous shear. Behera et al. analysed (Behera U., et al., 2005) the effect of nozzle geometry and number of nozzles. Standard k- $\varepsilon$ model was used and presence of secondary circulations was observed. Free and Forced vortex regimes were identified and it was concluded that 6-nozzles of convergent shape produce better results. Kazantseva et al. observed (Kazantseva, Piralishvili, \& Fuzeeva, 2005) formation of rotational vortex and secondary flows. Eiamsa-ard and Promvonge (Eiamsa-ard \& Promvonge, 2006) used ASM and Standard k- $\varepsilon$ model to model subsonic flow conditions in vortex tube, ASM and Standard k- $\varepsilon$ model results were compared with experimental to conclude that ASM is close to experiment. The reason of agreement is the ability of ASM to introduce non-isotropic turbulence effects. Skye et al. used (Skye, Nellis, \& Klein, 2006) RNG k-E turbulence model to with 2-D axisymmetric geometry. Skye demonstrated the application of CFD as a powerful tool to simulate the vortex tube problem. Farouk T. and Farouk B. applied (Farouk \& Farouk, 2007) LES turbulence model to vortex tube and concluded that LES can successfully simulate the conditions in vortex flow field and can give results very much close to measured ones. Akhesmeh et al. confirmed (Akheshmeh, Pourmahmoud, \& Sedgi, 2008) the accuracy of standard k- $\varepsilon$ model while working with 3-D sector model with standard k- $\varepsilon$ turbulence scheme. Behera et al. concluded (Behera U. , Paul, Dinesh, \& Jacob, 2008) that the reason of energy separation in vortex tube is shear work. Secchiaroli et al. investigated (Secchiaroli, Ricci, Montelpare, \& D'Alessandro, 2009) with RANS and LES models and predicted that there is significant variations in results with change in turbulence model the distributions of velocity, total temperature vary significantly. Dutta et al. compared (Dutta, Sinhamahapatra, \& Bandyopdhyay, Comparison of different turbulence models in predicting the temperature separation in a Ranque-Hilsch vortex tube, 2010) RANS, Standard k- $\varepsilon$, Standard k- $\omega$, and SST k- $\omega$ and predicted that results of Standard k- $\varepsilon$ are in close agreement with the experimental results. Shamsoddini and Nezhad (Shamsoddini \& Nezhad, 2010) investigated the effect of nozzle numbers on tube performance numerically and established relationship between power of cooling and nozzle numbers. The study concluded that with 40 to 1000 nozzles power of cooling increases from 98 to $100 \%$. There is substantial increase in power of cooling with increase in nozzle numbers. Baghdad et al. investigated (Baghdad M. , Ouadha, Imine, \& Addad, 2011) the energy separation with k- $\varepsilon, \mathrm{k}-\omega$, SST k- $\omega$ and RSM models and concluded that advanced RSM model accurately simulates the energy separation. Dutta et al. modelled (Dutta, Sinhamahapatra, \& Bandopadhyay, Numerical investigation of gas species and energy separation in the Ranque -Hilsch vortex tube using real gas model, 2011) air with NIST real gas approach and found that the results agree to that of ideal gas approach. Im and Yu (Im \& Yu, 2012) based on the experimental and numerical results did parametric optimization. Pourmahmoud et al. investigated (Pourmahmoud, Hassanzadeh, \& Moutaby, 2012) the effect of helical nozzle gap on cooling capacity using Standard k- $\varepsilon$ model and predicted that energy separation increases with increase in number of nozzles while, COP remains unaltered. Rafiee and Rahimi (Rafiee \& Rahimi, 2013) analyzed effect of convergence ratio and nozzle numbers on performance with Standard k- 
$\varepsilon$ model, the results shave shown that converging nozzle improve the performance of vortex tube. Bovand et al. numerically investigated (Bovand, Valipour, Dincer, \& Tamayol, 2014) the energy separation mechanism in curved vortex tubes, concluding that performance of straight tube is better than the curved tubes. Stagnation point was located in the curved tubes.

In case of numerical investigations with different fluids, many researchers (Bezprozvannykh \& Mottl, 1999; Farouk, Farouk, \& Gutsol, 2009; Pinar, Uluer, \& Kırmaci, 2009; Polat \& Kirmaci, 2011; Khazaei, Teymourtash, \& Jafarian, 2012; Baghdad, Ouadha, \& Addad, 2012; Thakare \& Parekh, 2014) have worked with variety of fluids. Farouk et al. applied (Farouk, Farouk, \& Gutsol, 2009) LES model for simulation of $\mathrm{N}_{2}$ and He mixture. It was observed that the inner core has large eddy heat flux and Reynolds stress. Pinar et al. optimized (Pinar, Uluer, \& Kırmaci, 2009) the tube using Taguchi approach. The optimization was carried out $\mathrm{A}_{\mathrm{r}}, \mathrm{O} 2$ and $\mathrm{N}_{2}$ as the working fluids. Polat et al. applied (Polat \& Kirmaci, 2011) ODFS (Output Dependent Feature Scaling) and ANFIS (Adaptive Network based Fuzzy Inference System) technique for predicting the performance of the vortex tube with Air, $\mathrm{O}_{2}, \mathrm{~N}_{2}$ and $\mathrm{He}$ as working fluid. Khazei et al. applied (Khazaei, Teymourtash, \& Jafarian, 2012) $\mathrm{CO}_{2}, \mathrm{Air}, \mathrm{He}, \mathrm{NH}_{3}$, Water vapour, $\mathrm{N}_{2}$ and $\mathrm{O}_{2}$ as working fluids to study effect of gas properties, it was observed that, Helium produces maximum energy separation on account of its lower molecular weight and maximum specific heat capacity ratio. The work was focussed on velocity and temperature distribution for tests with different turbulent models.

With reference to the literature, it was observed that most of the studies have addressed the effect of nozzle numbers and geometry variations. Many studies have also reported use of different gases to expand in the vortex tube without addressing the flow behaviour and its effect on energy separation. Literature also reports many theories proposed so far, but clear understanding of flow behaviour inside the vortex tube is unaddressed. Study of flow behaviour of different gases is intended to investigate the underlying mechanism and to study effect of gas properties on flow behaviour. With the necessity of axial and radial distribution of flow and energy parameters for different gases, it was proposed to work with a short straight diverging vortex tube to compare performance of different atomic gases i.e.Air, $\mathrm{He}, \mathrm{N}_{2}, \mathrm{CO}_{2}$ and $\mathrm{NH}_{3}$.

Present work differs from the literature in using combined straight and diverging tube with short L/D ratio and study of flow behaviour in radial and axial directions for different gases.

Tube geometry was used with combined straight and diverging section. A short tube with tube diameter $10 \mathrm{~mm}$ and length of $57 \mathrm{~mm}$ (L/D equal to 5.7) and divergence angle of $5.71^{\circ}$ and 2 nozzles were used for the study with different gases.

\section{Numerical Modelling}

Geometry of vortex tube is developed using appropriate mesh and boundary conditions. Standard k- $\varepsilon$, RNG k- $\varepsilon$, and Realizable k- $\varepsilon$ turbulent models were used initially for turbulence model selection. The conjugate differential equations are solved simultaneously using finite volume scheme of coupled algorithm. Pressure field inside the tube is obtained from calculations based on the inlet modelled as mass inlet, pressure and tube geometry. The model and the mesh is shown in Figure 1 and Figure 2.

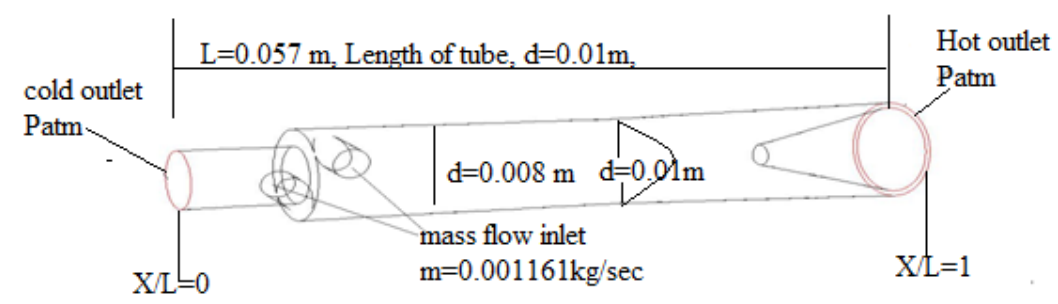

Figure 1. Schematic geometry of vortex tube 


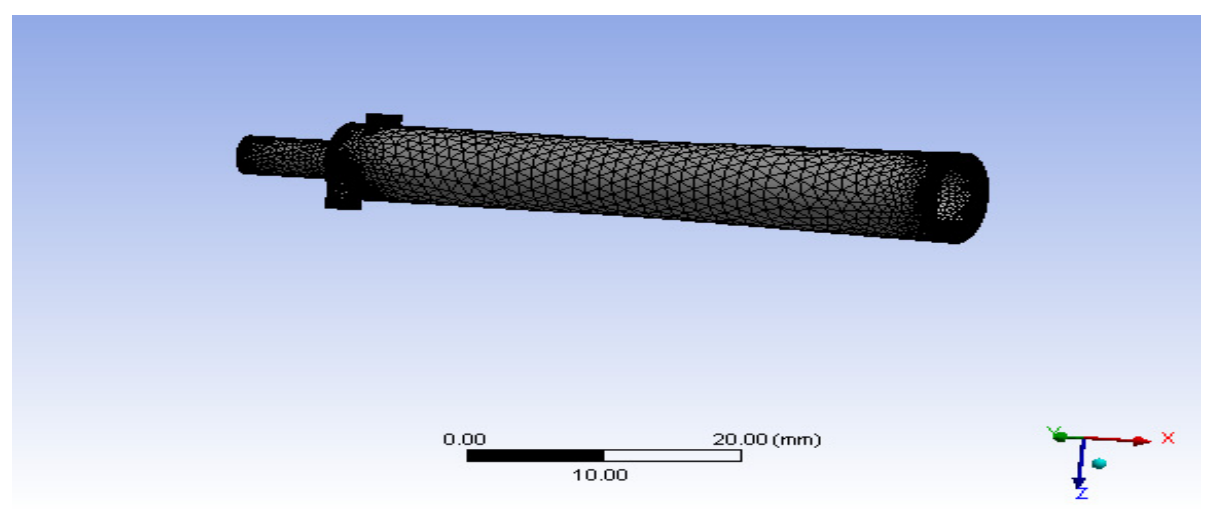

Figure 2. Computational domain with Mesh

\subsection{Governing Equations}

The numerical modelling of the vortex tube has been carried with the CFD code system of Fluent. For 3D compressible flow, the conservation of mass, momentum equations are given as:

Continuity equation:

$$
\frac{\partial \rho}{\partial t}+\nabla \cdot(\rho u)=0
$$

X-Momentum equation:

$$
\frac{\partial}{\partial \mathrm{t}}(\rho \mathrm{u})+\nabla \cdot(\rho \mathrm{u} \times \mathrm{u})=-\nabla \mathrm{P}+\nabla \cdot \tau+\mathrm{S}_{\mathrm{M}}
$$

Y-Momentum equation:

$$
\frac{\partial}{\partial t}(\rho v)+\nabla \cdot(\rho v \times v)=-\nabla P+\nabla \cdot \tau+S_{M}
$$

Z-Momentum equation:

$$
\frac{\partial}{\partial t}(\rho w)+\nabla \cdot(\rho w \times w)=-\nabla P+\nabla \cdot \tau+S_{M}
$$

\subsection{For Standard $k-\varepsilon$ Turbulence Model}

Turbulent Kinetic energy (k) equation:

$$
\frac{\partial}{\partial t} \rho k+\frac{\partial}{\partial x_{i}}\left(\rho k u_{i}\right)=\frac{\partial}{\partial x_{j}}\left[\left(\mu+\frac{\mu_{t}}{\sigma_{k}}\right) \frac{\partial k}{\partial x_{j}}\right]+G_{k}+G_{b}-\rho \varepsilon-Y_{M}+S_{k}
$$

Dissipation rate $(\varepsilon)$ equation:

$$
\frac{\partial}{\partial t}(\rho \varepsilon)+\frac{\partial}{\partial x_{i}}\left(\rho \varepsilon u_{i}\right)=\frac{\partial}{\partial x_{j}}\left[\left(\mu+\frac{\mu_{\mathrm{t}}}{\sigma_{\mathrm{k}}}\right) \frac{\partial \varepsilon}{\partial \mathrm{x}_{\mathrm{j}}}\right]+\mathrm{C}_{1 \varepsilon} \frac{\varepsilon}{\mathrm{k}}\left(\mathrm{G}_{\varepsilon}+\mathrm{C}_{3 \varepsilon} \mathrm{G}_{\mathrm{b}}\right)-\mathrm{C}_{2 \varepsilon} \rho \frac{\varepsilon}{\mathrm{k}}+\mathrm{S}_{\varepsilon}
$$

2.3 For RNG $k-\varepsilon$ Turbulence Model

Turbulent Kinetic energy (k) equation:

$$
\frac{\partial}{\partial t} \rho k+\frac{\partial}{\partial x_{i}}\left(\rho k u_{j}\right)=\frac{\partial}{\partial x_{j}}\left[\alpha_{k} \mu_{e f f} \frac{\partial \mathrm{k}}{\partial \mathrm{x}_{\mathrm{j}}}\right]+\mathrm{G}_{\mathrm{k}}+\mathrm{G}_{\mathrm{b}}-\rho \varepsilon-\mathrm{Y}_{\mathrm{M}}+\mathrm{S}_{\mathrm{k}}
$$

Dissipation rate $(\varepsilon)$ equation:

$$
\frac{\partial}{\partial t}(\rho \varepsilon)+\frac{\partial}{\partial x_{i}}\left(\rho \varepsilon u_{i}\right)=\frac{\partial}{\partial x_{j}}\left[\mathrm{C}_{1 \varepsilon} \mu_{e f f} \frac{\partial \varepsilon}{\partial \mathrm{x}_{\mathrm{j}}}\right]+\mathrm{C}_{1 \varepsilon} \frac{\varepsilon}{\mathrm{k}}\left(\mathrm{G}_{\mathrm{k}}+\mathrm{C}_{3 \varepsilon} \mathrm{G}_{\mathrm{b}}\right)-\mathrm{C}_{2 \varepsilon} \rho \frac{\varepsilon^{2}}{\mathrm{k}}-R_{\varepsilon}+\mathrm{S}_{\varepsilon}
$$

2.4 For Realizable $k-\varepsilon$ Turbulence Model

Turbulent Kinetic energy (k) equation: 


$$
\frac{\partial}{\partial t}(\rho k)+\frac{\partial}{\partial x_{j}}\left(\rho k u_{j}\right)=\frac{\partial}{\partial x_{j}}\left[\left(\mu+\frac{\mu_{t}}{\sigma_{k}}\right) \frac{\partial k}{\partial x_{j}}\right]+G_{k}+G_{b}-\rho \varepsilon-Y_{M}+S_{k}
$$

And

$$
\frac{\partial}{\partial t}(\rho \varepsilon)+\frac{\partial}{\partial x_{j}}\left(\rho \varepsilon u_{j}\right)=\frac{\partial}{\partial x_{j}}\left[\left(\mu+\frac{\mu_{t}}{\sigma_{\varepsilon}}\right) \frac{\partial \varepsilon}{\partial x_{j}}\right]+\rho C_{1} S_{\varepsilon}-\rho C_{2} \frac{\varepsilon^{2}}{k+\sqrt{v \varepsilon}}+C_{1 \varepsilon} \frac{\varepsilon}{k} C_{3 \varepsilon} G_{b}+S_{\varepsilon}
$$

Where, $C_{1}=\max \left[0.43, \frac{\eta}{\eta+5}\right], \eta=S \frac{k}{\varepsilon}, S=\sqrt{2 S_{i j} S_{i j}}$

$\mathrm{G}_{\mathrm{k}}, \mathrm{G}_{\varepsilon}$ Represent the generation of turbulence kinetic energy due to the mean velocity gradients, generation of $\varepsilon$ respectively. $G_{b}$ is the generation of turbulence kinetic energy due to buoyancy, $Y_{M}$ represents the contribution of the fluctuating dilatation in compressible turbulence to the overall dissipation rate and $\mathrm{C}_{1 \varepsilon}, \mathrm{C}_{2 \varepsilon}, \mathrm{C}_{3 \varepsilon}$ are constants and $\rho k, \rho \varepsilon$ are turbulent Prandtl numbers for $\mathrm{k}$ and $\varepsilon$ respectively and $\alpha_{k}, \alpha_{\varepsilon}$, are the inverse effective Prandtl numbers for $\mathrm{k}$ and $\varepsilon$ respectively $\mathrm{S}_{\mathrm{k}}, \mathrm{S}_{\varepsilon}$ are the user defined source terms.

$G_{k}=\mu_{t} S^{2}$, where, $S=\sqrt{2 S_{i j} S_{i j}} \cdot G_{b}$, is the generation of turbulent kinetic energy due to buoyancy is given by,

$$
\begin{gathered}
G_{b}=\beta g_{i} \frac{\mu_{t}}{P_{r_{T}}} \frac{\partial T}{\partial X_{i}} \\
\mathrm{C}_{1 \varepsilon}=1.44, \mathrm{C}_{2 \varepsilon}=1.92, \mathrm{C}_{\mu}=0.09, \sigma_{k}=1.0, \sigma_{\varepsilon}=1.3 .
\end{gathered}
$$

$\mathrm{C}_{3} \varepsilon=1$ for flow direction aligned with gravity

$\mathrm{C}_{3} \varepsilon=0$ for flow direction that is perpendicular to the direction of gravity.

\subsection{Boundary Conditions}

In present numerical simulation of vortex tube boundary conditions used are as shown in the Table 1 shows the geometry and boundary conditions. For all planes i.e. pressure outlet boundary condition $\mathrm{P}=\mathrm{P}_{\infty}, \mathrm{T}=\mathrm{T}_{\infty}$ and $\rho=\rho_{\infty}$ is imposed. For wall boundary condition $u=v=0 \mathrm{~ms}^{-1}$ and adiabatic wall is considered. No slip boundary condition is applied to all remaining planes that are walls. Free stream temperature is assumed $25^{\circ} \mathrm{C}$. The operational pressure is taken as $101325 \mathrm{Nm}^{-2}$. The boundary conditions are detailed in Table 1 .

Table 1. Geometry boundary conditions

\begin{tabular}{lll}
\hline Part Name & Geometry & Boundary Conditions \\
\hline Inlet & $\mathrm{r}=\mathrm{R}, \mathrm{x}=10 \mathrm{~mm}$ & Mass flow \\
Cold outlet & $\mathrm{x}=0 \mathrm{~mm}, \mathrm{P}=1 \mathrm{bar}$ & Pressure outlet \\
Hot outlet & $\mathrm{x}=57 \mathrm{~mm}, \mathrm{P}=1 \mathrm{bar}$ & Pressure outlet \\
Wall & $\mathrm{r}=\mathrm{R}, \mathrm{x}=0$ to $57 \mathrm{~mm}$ & Adiabatic wall, No slip \\
\hline
\end{tabular}

\section{Method of Solution}

The governing Eqs. (1-3, 6, 8) are discretized using finite volume method with a staggered grid. The convective terms are discretized using second order upwind discretization technique. The solution algorithm used in this work is SIMPLE.

\subsection{Grid Dependency Study}

Grid dependency study helps in predicting effect of grid size value on the solution convergence and the results. One of the of grid dependency study is to check the magnitude of error term between two successive iterations for different grid values. Another approach is to monitor a solution variable for different grid size values. 3D vortex tube was analysed using the second approach for different grid numbers as shown in Table 2. The results are compared with experimental results of Devade and Pise (Devade \& Pise, 2014). The simulations were carried out for mesh having 247863 - 425476 cells. Figure 3 show grid size comparison. It shows that cold end temperature deviation is $9 \%$ as compared to experimental results for grid size of 357540 . Beyond this grid size, the solution does not vary much with change in grid size. This means, the solution is independent of grid size. Hence, 357540-grid size was used for numerical solution. 


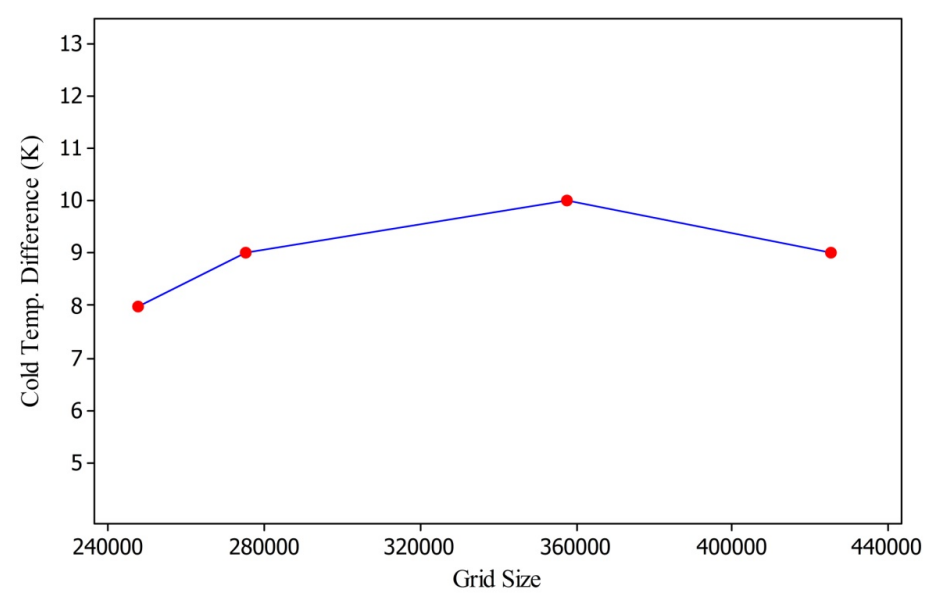

Figure 3. Grid size comparison

Table 2. Grid size comparison chart

\begin{tabular}{llllll}
\hline & Grid I & Grid II & Grid III & Grid IV & Exp. \\
\hline No of Cells & 247863 & 275424 & $3,57,540$ & $4,25,476$ & \\
$\Delta \boldsymbol{T}_{\boldsymbol{c}}$ & 6 & 9 & 10 & 9 & 11 \\
Deviation & 0.454 & 0.181 & 0.090 & 0.181 & \\
\hline
\end{tabular}

\subsection{Turbulence Model Selection}

For selection of turbulence model, Standard k- $\varepsilon$, RNG k- $\varepsilon$ and Realizable k- $\varepsilon$ turbulence models were used for solution and their results are compared with experimental results of Devade and Pise (Devade \& Pise, 2014) as shown in Figure 4 The Realizable k- $\varepsilon$ turbulence model shows close agreement with experimental results. Hence, Realizable k- $\varepsilon$ model was selected for simulation.

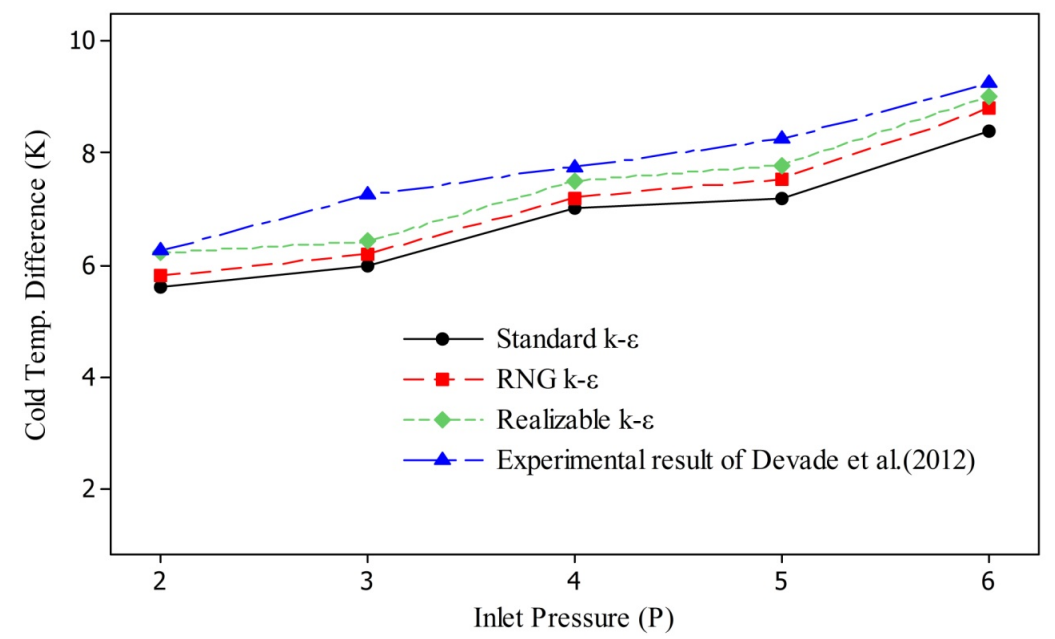

Figure 4. Comparison of RANS turbulence model with experimental results

\subsection{Numerical Modeling with Different Fluids}

Literature shows that numerical methods are mainly used for capturing the flow physics and the separation phenomenon in vortex tube. Most of the numerical studies have used air as working fluid. For the present study along with air, other multi-atomic gases were tested, that are commonly used in refrigeration applications. The various fluids that are used for testing are, air, Helium (Mono-atomic), Nitrogen (Di-atomic), Carbon dioxide (Tri-atomic) and Ammonia $\left(\mathrm{NH}_{3}\right)$. The properties of all these fluids are listed in Table 3 . All these selected fluids are compressible in nature and energy separation in case of compressible fluids is higher (Deissler \& Perlmutter, 1960) compared to perfect gases. 
Table 3. Properties of different fluids

\begin{tabular}{llllllll}
\hline Fluid & Chemical formula & Density & Viscosity & Kine. Visco. & Gas Constant & Specific heat ratio & Molecular weight \\
\hline & & $\mathrm{Kgm}^{-3}$ & $\mathrm{~Pa}-\mathrm{s}$ & $\mathrm{m} 2 \mathrm{sec}^{-1}$ & $\mathrm{JKg}^{-1}-\mathrm{k}^{-1}$ & & $\mathrm{Kgmol}^{-1}$ \\
Air & - & 1.09 & $1.95 \times 10-5$ & $1.79 \times 10-5$ & 287 & 1.4 & 29 \\
Nitrogen & $\mathrm{N} 2$ & 1.0566 & $1.89 \times 10-5$ & $1.78 \times 10-5$ & 297 & 1.4 & 14 \\
Helium & $\mathrm{He}$ & 0.15124 & $2.09 \times 10-5$ & $1.3844 \times 10-5$ & 2080 & 1.667 & 4 \\
Carbon Dioxide & $\mathrm{CO} 2$ & 1.6356 & $1.58 \times 10-5$ & $9.71 \times 10-6$ & 189 & 1.289 & 44 \\
Ammonia & $\mathrm{NH}_{3}$ & 0.769 & $2.76 \times 10-5$ & $1.0173 \times 10-5$ & 488 & 4.67 & 17.031 \\
\hline
\end{tabular}

Short tube with $\mathrm{L} / \mathrm{D}=6$ and tube diameter $10 \mathrm{~mm}$ was used for a length of $57 \mathrm{~mm}$ and combination of straight and diverging section with a divergence angle of $5.71^{\circ}, 2$ nozzles and hot end valve angle of $45^{\circ}$ was used. 3-D geometry of above dimension was created as domain for the numerical solution.

With the set boundary conditions, fluids were tested for analyzing the effect of these fluids on thermal performance of the vortex tube. The effect of all fluids was analyzed for total temperature, total pressure, tangential velocity, density, viscosity and turbulence intensity distribution.

\section{Results and Discussion}

Flow behaviour and energy separation for different gases is analyzed with axial and radial distribution of pressure, temperature and tangential velocity. Radial distribution of fluid properties and turbulence intensity is analyzed. Discussion also includes energy separation and heat transfer rates for all gases.

\subsection{Total Pressure}

Total pressure is given by the following formula, it considers the temperature on the basis of energy content.

$$
P_{t}=P+\rho \frac{v^{2}}{2}
$$

\subsubsection{Axial Distribution}

Figure 5 shows the axial distribution of total pressure for all gases from cold end $(\mathrm{X} / \mathrm{L}=0)$ and hot end $(\mathrm{X} / \mathrm{L}=1)$. Total pressure is high at inlet and then it decreases towards cold and hot outlets. The initial increase in total pressure and the sudden drop, indicates that the intensity of energy separation is higher at the entrance of the tube upto length $(\mathrm{X} / \mathrm{L}=0.062$ to $\mathrm{X} / \mathrm{L}=0.42)$ while, it decreases towards hot end. The axial pressure drop indicates the swirl decay along the length and approaches to static conditions at outlets.

Comparative study of total pressure distribution Figure 6 with Behera et al. shows (Behera U., Paul, Dinesh, \& Jacob, 2008) that obtained results are in close agreement upto $\mathrm{X} / \mathrm{L}=0.67$. Normalized total pressure is compared. The deviation on hot end side is attributed to the dimensional variations.

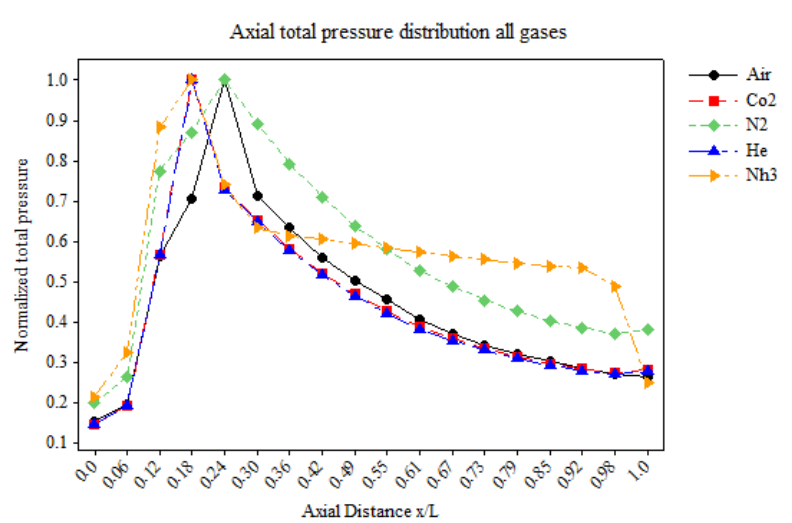

Figure 5. Axial total pressure distribution for all gases

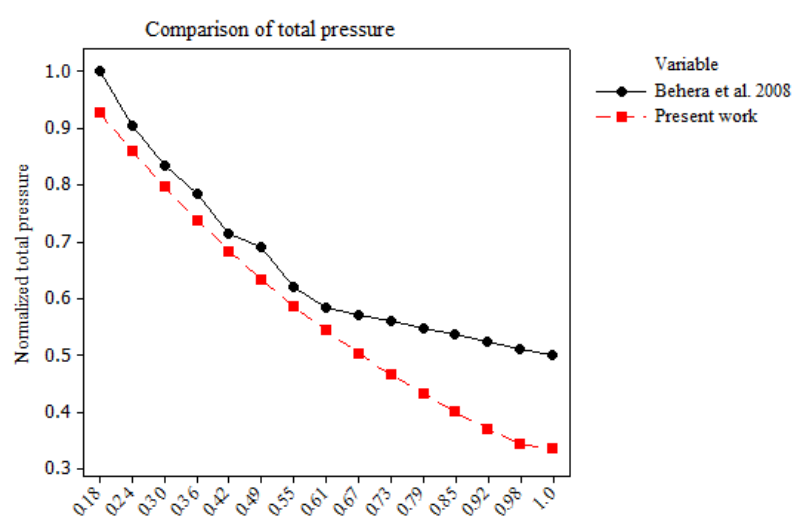

Figure 6. Comparison of total pressure distribution for all gases 


\subsubsection{Radial Distribution}

Figure 7 shows the radial total pressure distribution of all fluids. It is seen that the total pressure at cold end $(\mathrm{X} / \mathrm{L}=0)$ and hot end $(\mathrm{X} / \mathrm{L}=1)$ is lower than the other locations inside the tube. The total pressure on cold end is lower because of lower velocities and low temperatures. Radial pressure gradient exists inside the tube. Highest-pressure gradient is seen at $\mathrm{X} / \mathrm{L}=0.25$ (close to cold end). Thus, there is maximum energy separation at the entrance zone. Then onwards the radial pressure gradient decreases at all axial locations. The reason for radial gradient decrease is attributed to the decay in velocity. Similar trends of pressure distribution are observed for all the gases except $\mathrm{NH}_{3}$ because of its high viscosity and specific heat.
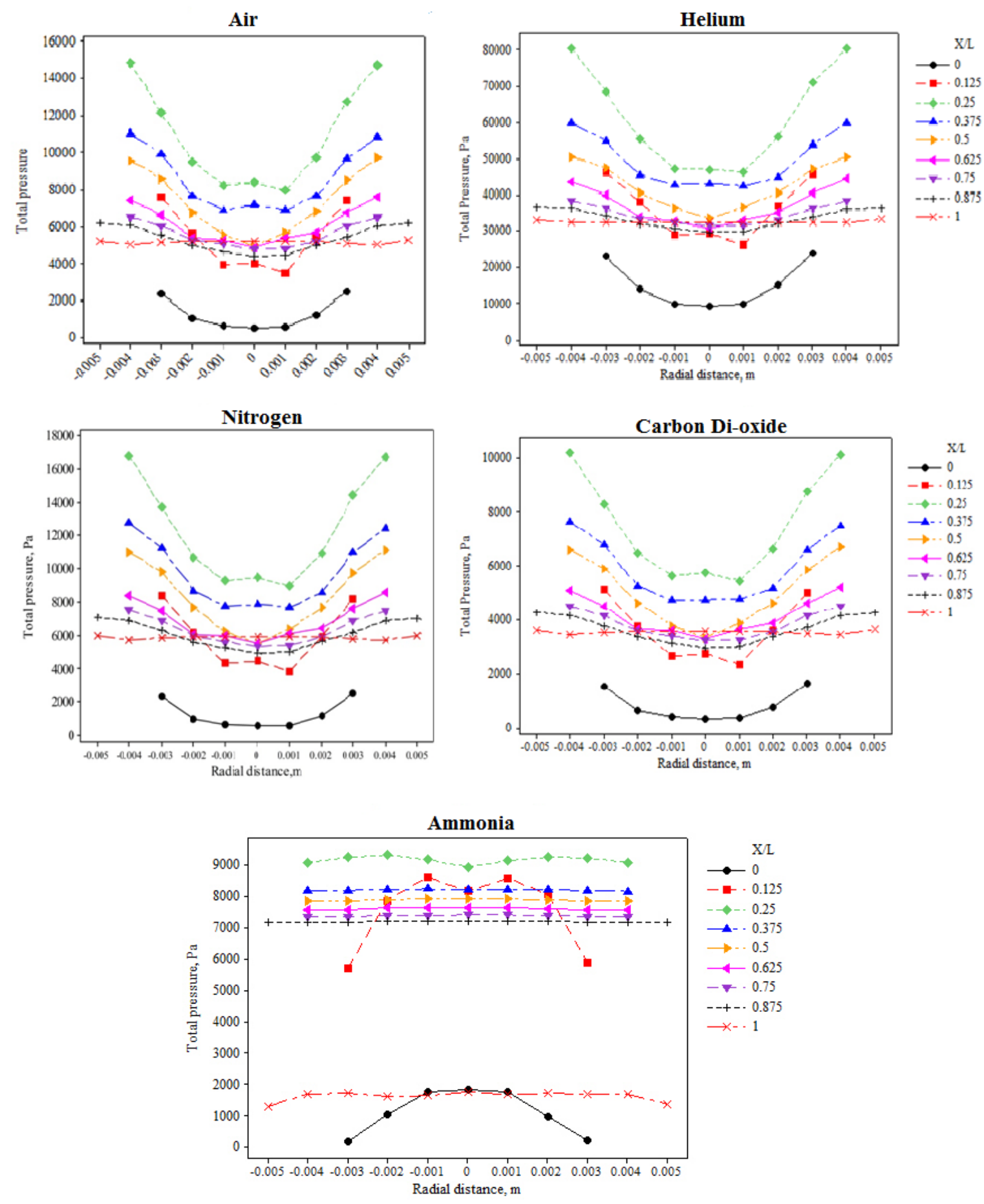

Figure 7. Radial distribution of total pressure 
The total pressure is highest for Helium. The high pressure for helium is because of higher velocity of helium inside the tube. Helium being low-density gas, its velocity is higher than the other fluids. Total pressure and energy separation for $\mathrm{N}_{2}$ and $\mathrm{He}$ are higher as compared to other fluids.

Since the pressure gradient along the radial plane is higher only at the inlet and the regions close to inlet. The total pressures existing in the tube for fluids are much lower. The magnitude of radial pressure gradient for all gases shows significant effects of compression and expansion. It can be seen that the radial gradient of total pressure decreases along the axis. The existence of radial gradient indicates the expansion and compression effects. Total pressure increases from core to periphery. The radial gradient can be seen from $\mathrm{X} / \mathrm{L}=0$ to $\mathrm{X} / \mathrm{L}=0.75$ Thus the Ranque's (Ranque, 1933) hypothesis for compression and expansion can be justified. At $X / L=0.875$ and 1 the pressures are nearly static.

As seen from Figure 7 radial pressure gradient decreases with increase in $\mathrm{X} / \mathrm{L}$. It is the obvious pressure drop along the axis for a swirling flow (swirl decay); this limits the use of higher $\mathrm{L} / \mathrm{D}$ ratio.

Radial pressure gradient is insignificant at both ends. Although the radial pressure distribution is insignificant there exists a smaller additional energy transfer because of expansion and contraction of eddies in a radial pressure gradient (Deissler \& Perlmutter, 1960).

- The radial pressure gradient in case of $\mathrm{He}$ and $\mathrm{N}_{2}$ is maximum compared to air, $\mathrm{CO}_{2}$ and $\mathrm{NH}_{3}$.

- This presents the reason for good performance of $\mathrm{He}$ and $\mathrm{N}_{2}$ for energy separation. The energy separation for $\mathrm{N}_{2}$ and $\mathrm{He}$ is higher than $\mathrm{CO}_{2}$ and air. Low density of Helium and high specific heat of $\mathrm{N}_{2}$ is responsible for higher energy separation than the other fluids.

\subsection{Total Temperature}

Total temperature of a compressible fluid is given by,

$$
T=T_{s t}\left(1+\frac{\gamma-1}{2} M^{2}\right)
$$

For compressible fluids, total or stagnation temperature depends on the process by which the fluid comes to rest. If the fluid is brought to rest isentropically, the total and static temperatures will be same. In other cases, the total temperature will be higher because of friction [29]. This results in conversion of kinetic energy into heat and ultimately, temperature at the point is higher than static temperature (ordinary temperature of fluid with negligible kinetic energy). Thus, total temperature or stagnation temperature is also given as,

$$
T_{\text {total }}=T_{\text {stat }}+\frac{V^{2}}{2 C_{p}}
$$

The next section deals with axial and radial distribution of total temperature.

\subsubsection{Axial Distribution}

Axial distribution of total temperature shows magnitude of the energy separation. Figure 8 shows the total temperature distribution along the axis for air. The maximum and minimum total temperature variations are plotted along the axis. Maximum axial temperature gradient is at $X=0$ until $X=0.0285$ i.e. midpoint of the axial length, but the temperature gradient decreases along the axis. The maximum gradient is at the entry of fluid in the vortex tube.

Figure 9 shows the axial total temperature for all fluids. The Gases $\mathrm{He}, \mathrm{N}_{2}$ and $\mathrm{CO}_{2}$ give minimum total temperatures because of the low specific heat ratio respectively while, for air and $\mathrm{NH}_{3}$ shows higher total temperatures, due to higher viscosity.

Figure 10 shows that the total temperature goes on increasing along the axis. The results for air are compared with the Behera et al. (Behera U., Paul, Dinesh, \& Jacob, 2008). The comparison shows that the obtained results are in good agreement. The total temperature gradient varies inversely with the axial length. 


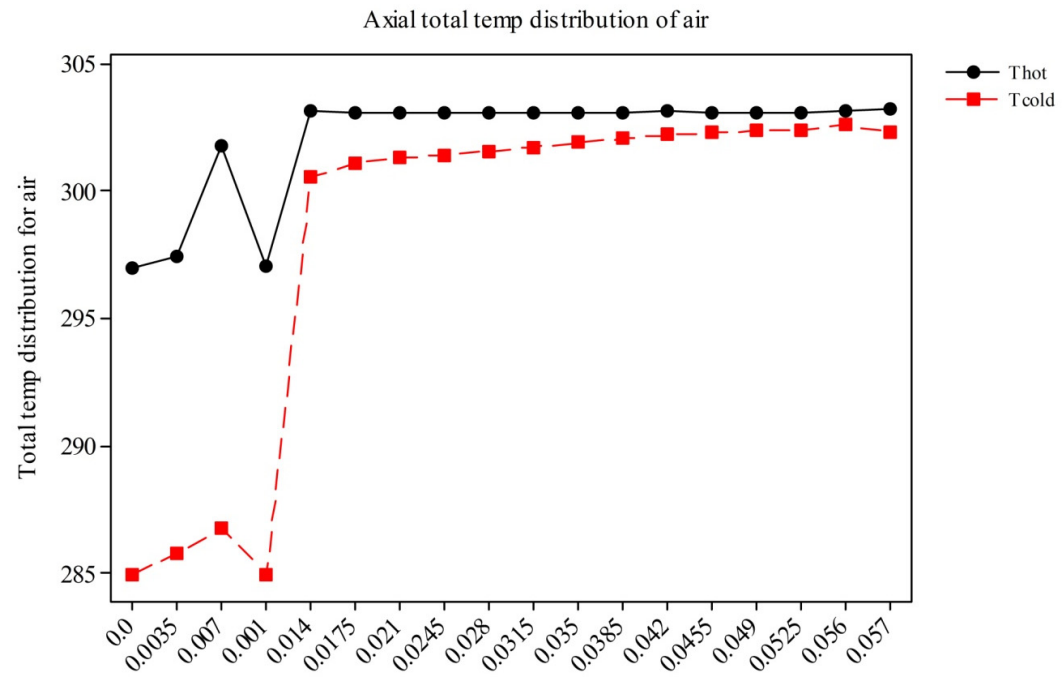

Figure 8. Variations of maximum and minimum total temperature distribution along length

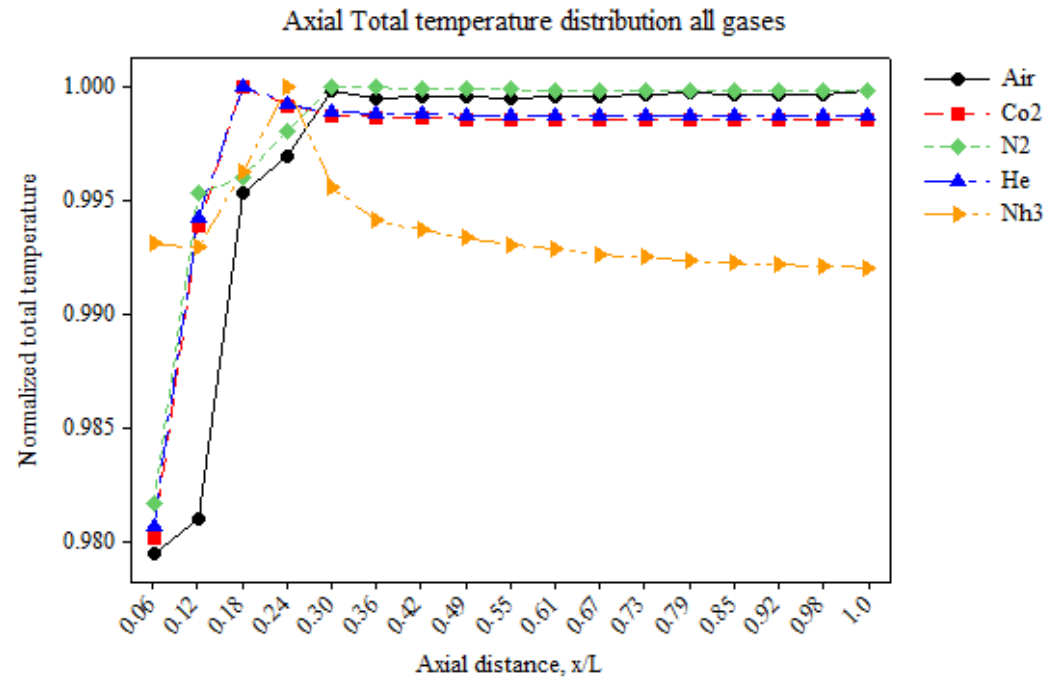

Figure 9. Total temperature axial distribution for all gases

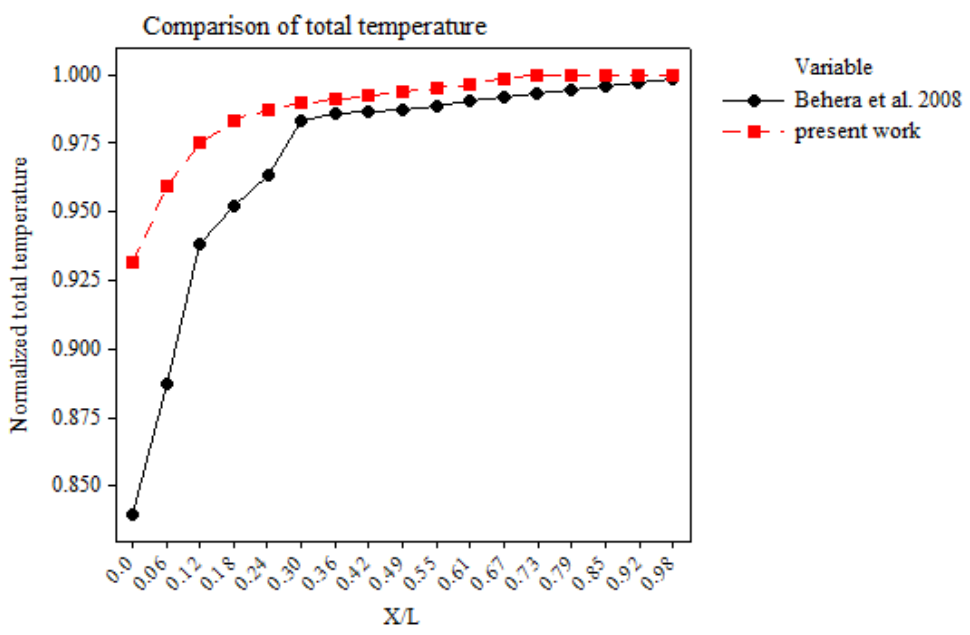

Figure 10. Variation of normalized total temperature distribution for air 


\subsubsection{Radial Distribution}

Figure 11 shows the radial distribution of total temperature for all gases along the different axial locations. It shows the radial temperature gradients inside the vortex tube.
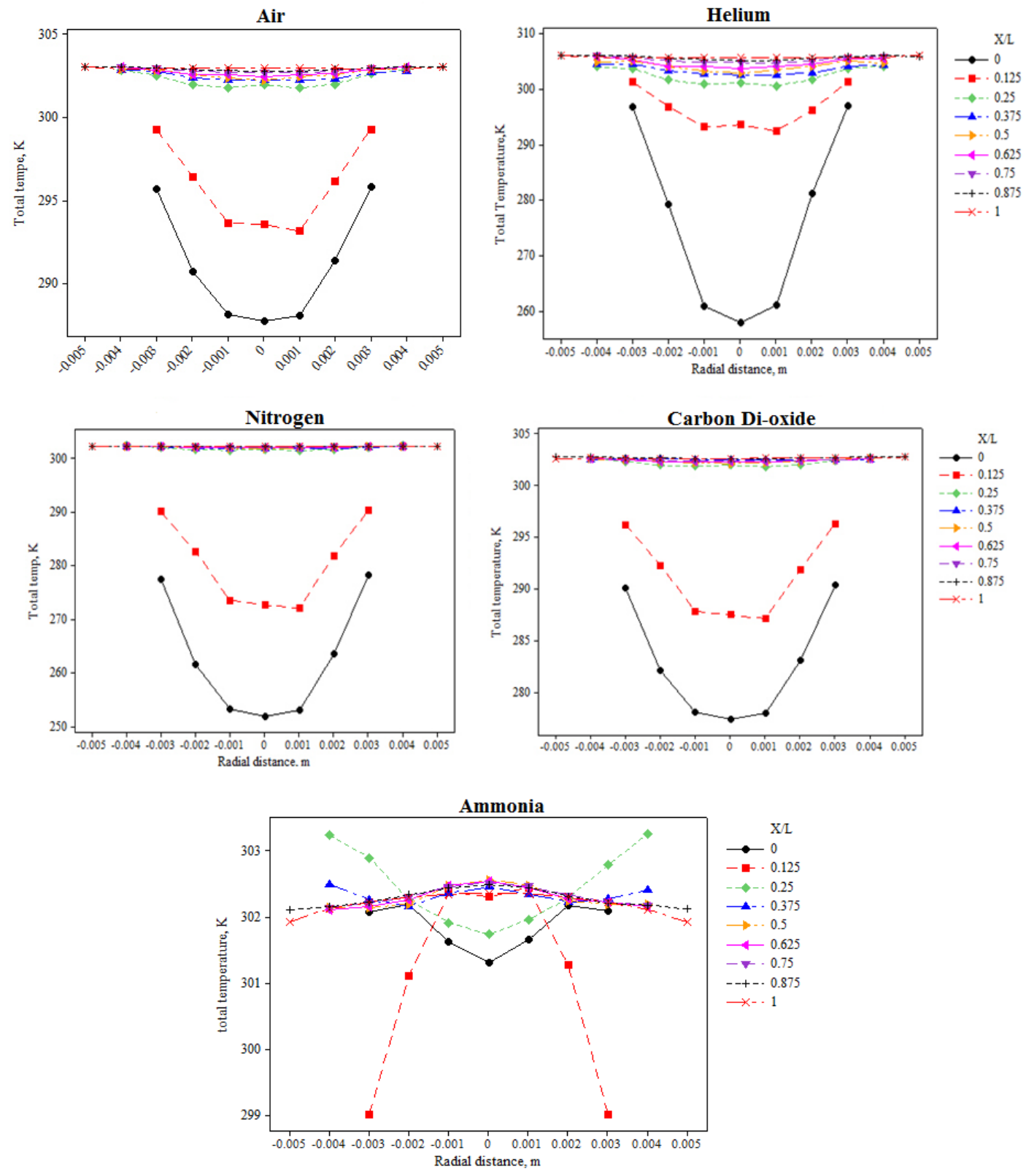

Figure 11. Radial distribution of total temperature for all gases

The radial contours of total temperature show that, from a certain axial length onwards heating is more prominent. High temperatures occur towards hot end. While, towards cold end there is presence of radial temperature gradient increased from core to periphery. The intensity of radial temperature gradient decreases along axis towards hot end. The major temperature gradient is observed at $\mathrm{X} / \mathrm{L}=0$ i.e. the cold end of the vortex tube and $\mathrm{X} / \mathrm{L}=0.125$ a section just ahead of the cold end. For all other locations inside the tube along the length, the temperature gradient is not that significant. Temperatures along the radial plane are more or less constant. The above observations are similar to the observations of Gutsol (Gutsol, 1997). Gutsol reported that the core stream has minimum energy on the tube axis near the nozzle section and the maximum energy near the hot stream outlet and that the radial difference of the total temperature peaks at the nozzle section. 
The radial distribution of total temperature as shown in Figure 11 clearly shows that at $\mathrm{X} / \mathrm{L}=0$ and at $\mathrm{X} / \mathrm{L}=0.125$ the magnitude of temperature gradient is significant it rises from core to periphery. Thus maximum energy separation occurs in this region. The reason for maximum energy separation in this region is the fluid enters tangentially inside the tube at this section and it interacts with the reversed core stream. As seen the radial temperature distribution shows that total temperature at the centre of the tube is lower at all axial locations than the periphery.

Heat transfer theory proposed by Scheper (Scheper, 1951) states that heat transfer takes place from core to periphery because of positive total temperature gradient. From Figure 11, for all gases the radial temperature gradient is negative hence the heat transfer theory is not justified.

Radial distribution of total temperature for all gases is similar except $\mathrm{NH}_{3}$. Total temperature is lowest for $\mathrm{He}, \mathrm{N}_{2}$ and $\mathrm{CO}_{2}$ followed by air and $\mathrm{NH}_{3}$. The magnitude of radial temperature distribution for all gases is different.

\subsection{Tangential Velocity}

As the compressed fluid enters tangentially in the vortex tube and travels in spiral motion along the periphery and at the core, the distribution of tangential velocity may address the energy separation mechanism in vortex tube. The axial distribution of tangential velocity is as shown in Figure 12.

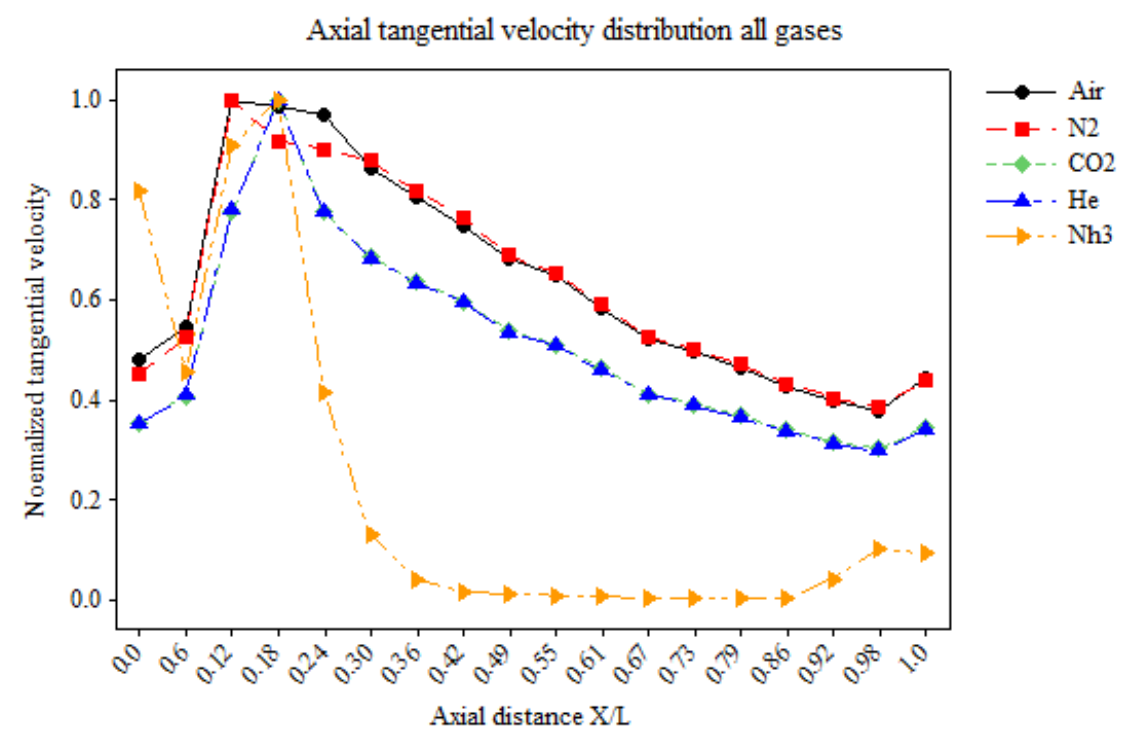

Figure 12. Axial distribution of tangential velocity all gases

\subsubsection{Axial Distribution}

The Figure 12 shows that tangential velocity increases up to inlet section and then goes on decreasing along the axis, i.e. peripheral stream may be gaining heat at the loss of kinetic energy. The highest tangential velocity is noticed at $\mathrm{X} / \mathrm{L}=0.125$ which is a zone just close to inlet section. Thus, highest tangential velocity is at inlet and then towards hot and cold end the tangential velocities are lower.

The comparisons of the obtained results with the literature show the similar trend. The results obtained are in good agreement. Figure 13 shows axial decay is tangential velocity. The tangential velocity decay is in contrast to the total temperature plots. It can be said that the tangential velocities govern the energy separation inside the vortex tube.

As tangential velocity decreases along the axis, it becomes necessary to check the radial distribution of the same, as the core stream may be losing heat to gain kinetic energy and being cooled.

\subsubsection{Radial Distribution}

Air enters the vortex tube tangentially it swirls close to periphery and at the core, because of tangential velocity. Figure 14 shows the radial distribution of tangential velocities in different radial planes along the axis. The variation of tangential velocity along radial plane leads to shearing because of velocity differences in the fluid.

The core stream is at lower tangential velocities than peripheral streams. It can be seen that tangential velocity goes on increasing along the radius of the tube in positive and negative $\mathrm{Y}$ directions. Higher tangential velocities occur at the hot and cold end $(\mathrm{X} / \mathrm{L}=0,1)$. For other axial lengths, intensity of tangential velocity gradient is less. 
Tangential velocity distribution shows that the core stream gains kinetic energy from the peripheral stream and loses heat to peripheral stream thus heating the peripheral stream and lowering its own temperature. This effect is higher at cold end and decreases along the axis towards hot end. Tangential velocity is responsible for creating the tangential shear stress and it may be the reason of energy separation. As seen from the radial distribution of tangential velocity for air, at $\mathrm{X} / \mathrm{L}=0$ i.e. cold end of the tube there is forced vortex until periphery where velocity is directly proportional with radius of the tube. Moreover, at $\mathrm{X} / \mathrm{L}=1$, there is forced vortex upto $\mathrm{r}=0.004$ and then onwards free vortex is observed, for free vortex velocity is inversely proportional to radius of the tube. At all axial locations inside the tube, the tangential velocity changes from free to forced vortex. This may cause energy separation, as at $\mathrm{r}=0$ the intensity of tangential velocity is very less and lower temperatures are observed at core.

As tangential velocity increases radially, because of radial gradient of tangential velocities, tangential shear of the air stream may be the reason for energy separation. The similar profiles of tangential velocity distribution are observed for all other fluids. Deissler and Perlmutter (Deissler \& Perlmutter, 1960) in a study have shown dependency of energy separation on tangential velocity. Linderstrom-Lang (Linderstrom-Lang, 1971) also observed that total temperature gradient is sensitive to the changes in radial distribution of tangential velocity.

Tangential velocities for He are higher. Due to higher tangential velocities, the energy separation is high for helium. The velocity distribution for all fluids has similar profile but different magnitude. The highest magnitude of velocity is for $\mathrm{He}$ followed by $\mathrm{N}_{2}$, Air, $\mathrm{CO}_{2}$ and $\mathrm{NH}_{3}$. The lowest magnitude of tangential velocity is for $\mathrm{CO}_{2}$ being a dense gas than all other fluids.

In almost all gases, free and forced vortex exists in the flow field. At hot end i.e. $(X=0.057$ or $X / L=1)$ at $R=0.004$, the tangential velocity is higher, At centre of the tube along the axis tangential velocity is zero and it increases with radius upto $\mathrm{r}=0.004$, this region indicates forced vortex $\left(\left(v \propto r^{1}\right)\right.$, beyond $\mathrm{r}=0.004$, near the wall free vortex is seen where velocity is inversely proportional to radius. At all other sections existence of free and forced vortex is clearly seen. At the cold end $(\mathrm{X}=0)$, there exists only forced vortex, as the velocity is directly proportional to radius along the entire radial plane. The appearance of free vortex $\left(v \propto r^{-1}\right)$, indicates that region of positive shear work and increase of total temperature.

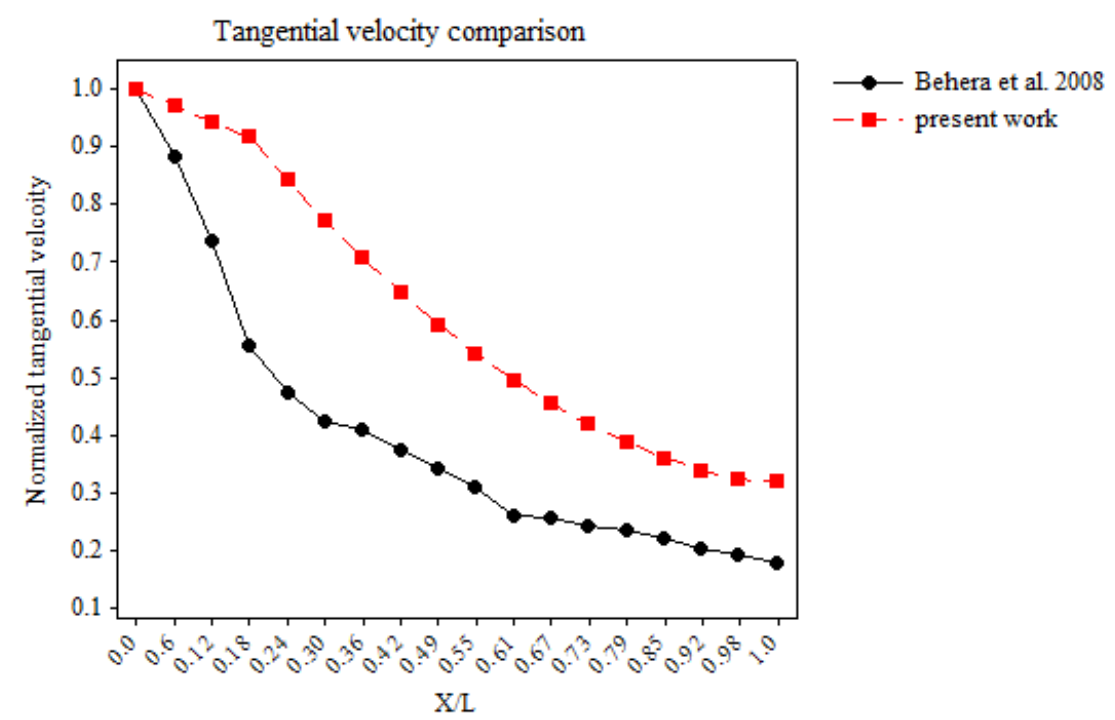

Figure 13. Comparison of axial distribution of tangential velocity for air 

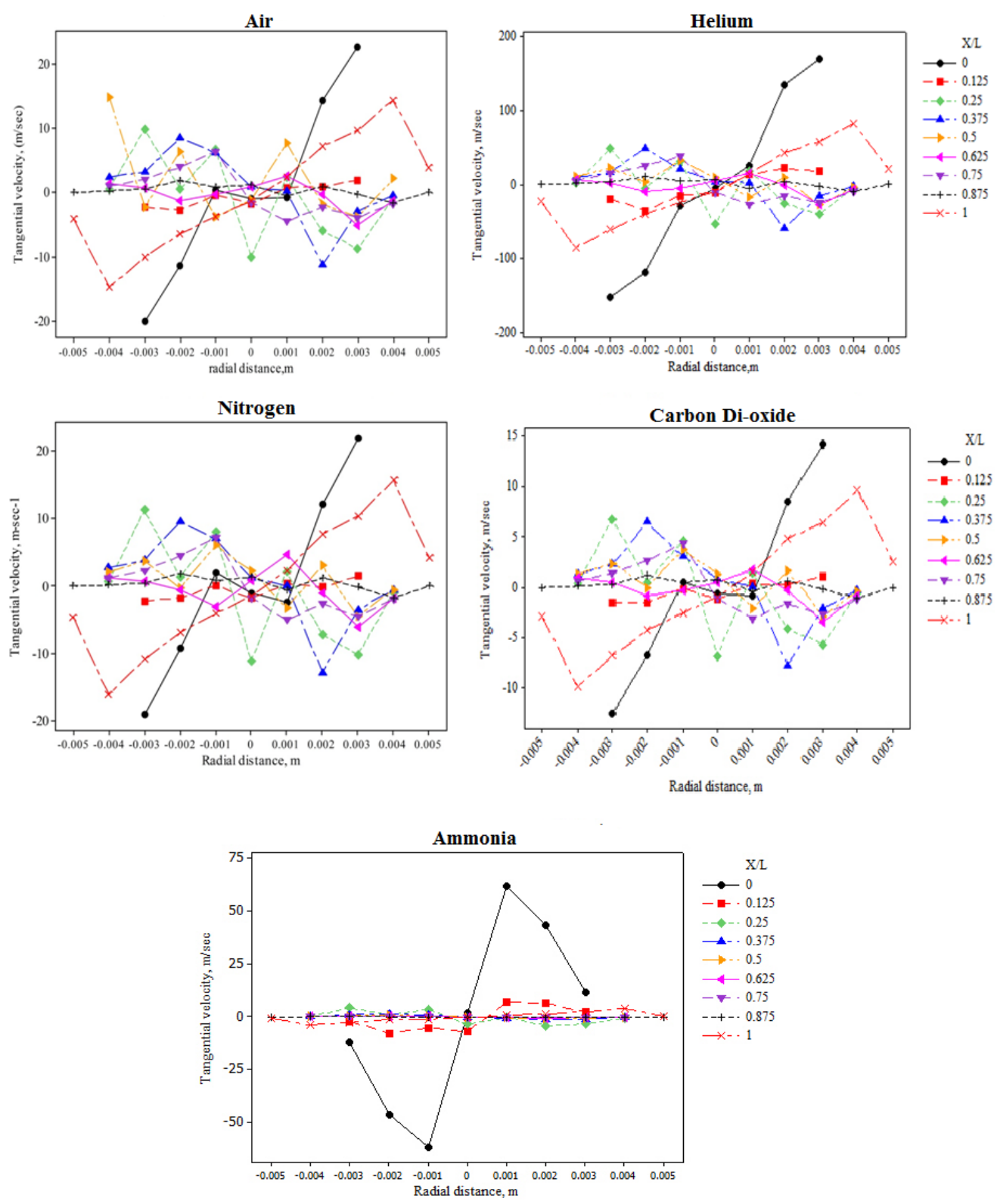

Figure 14. Radial distribution of Tangential velocity

\subsection{Radial Distribution of Density}

Radial distribution of density for all gases is as shown in Figure 15. The gases are assumed real and density variations are according to Redlich-Kwong (Redlich \& Kwong, 1949) equation of states. The equation of states is given as,

$$
P=\frac{R T}{V-b}-\frac{a}{V(V+b) T^{0.5}}
$$

Where the coefficients $a=0.4278 \frac{R^{2} T_{c}^{2.5}}{P_{c}}$ and $b=0.0867 \frac{R T_{c}}{P_{c}}$ b.

Figure 15 shows that, at cold and hot ends, the density gradient is positive and for all other axial locations, the density gradient is negative from core periphery. Inside the tube, density has radial gradient. At periphery, the density is higher than at the core. At cold end, core is highly dense than periphery, indicating the cold stream formation with densely packed fluid stream. The radial gradient of density at all sections along the axis, indicate the presence of strong centrifugal force. The centrifugal force throws the fluid mass towards the periphery making it denser than the core, similar to the impeller eye of the pump. 

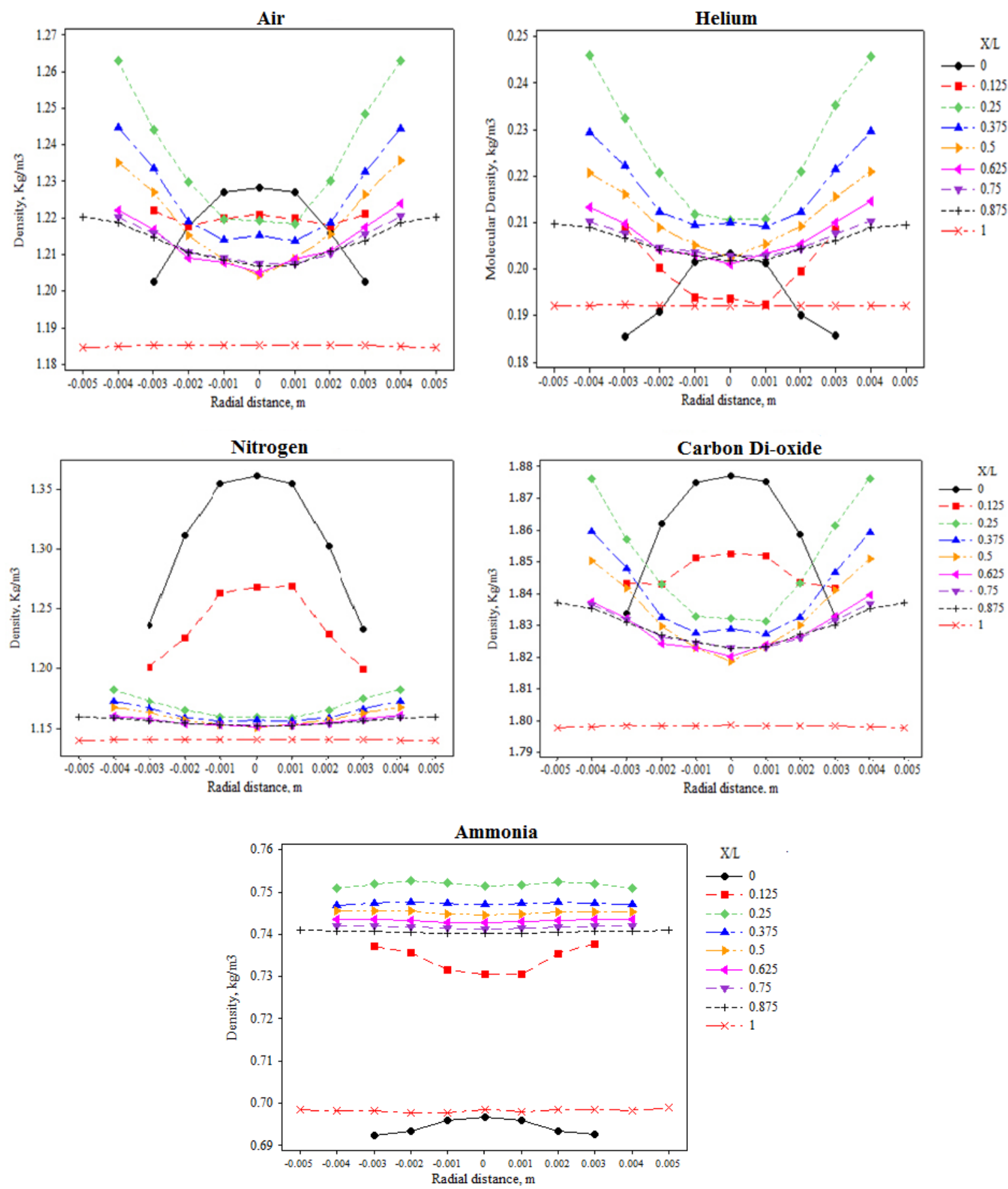

Figure 15. Radial distribution of density

Density distribution for all gases has similar profiles except for $\mathrm{He}$ and $\mathrm{NH}_{3}$, the variation in density distribution for these fluids is because of low densities as compared to $\mathrm{N}_{2}, \mathrm{CO}_{2}$ and air. Figure 13 shows that the density distribution may be a factor of energy separation, for helium density gradient is less at core and higher at periphery but the intensity of gradient is different at every section. Density gradient and density distribution increases from $\mathrm{X} / \mathrm{L}=0$ to $\mathrm{X} / \mathrm{L}=0.25$ and at $\mathrm{X} / \mathrm{L}=0.375$ it again drops upto $\mathrm{X} / \mathrm{L}=1$ thus the tube is getting divided axially into low density and high density zones. This may introduce mixing of the streams because of the density differences.

\subsection{Radial Distribution of Viscosity}

Distribution of viscosity shows the flow behaviour inside the vortex tube. The viscosity variations are according to Sutherland's law of viscosity (Sutherland, 1893). The Sutherlands viscosity law is as follows, 


$$
\mu=\mu_{\text {ref }}\left(\frac{T}{T_{\text {ref }}}\right)^{3 / 2} \frac{T_{\text {ref }}+S}{T+S}
$$

Figure 16 shows presence of low viscosity at the core and higher viscosity at periphery. For air, N2 and CO2 similar tends are seen. The profiles of viscosity for NH3 and He are different from the other fluids as their viscosities are higher. Viscosity distribution near cold end i.e. $\mathrm{X} / \mathrm{L}=0$ and $\mathrm{X} / \mathrm{L}=0.125$ shows parabolic distribution of viscosity, higher viscosity at periphery is because of the no-slip conditions applied at the wall. The distribution of viscosity shows that there exists a axial gradient of viscosity from hot end to cold end. i.e. from $\mathrm{X} / \mathrm{L}=0.5$ to $\mathrm{X} / \mathrm{L}=0.875$ the viscosities are higher, and from $\mathrm{X} / \mathrm{L}=0.5$ to $\mathrm{X} / \mathrm{L}=0.25$ the viscosity is low. There are high viscous and low viscous zones inside the vortex tube, These zones may be responsible for the Multiple circulations as stated by Xue et al. (Xue, Arzomandi, \& Kelso, 2011).
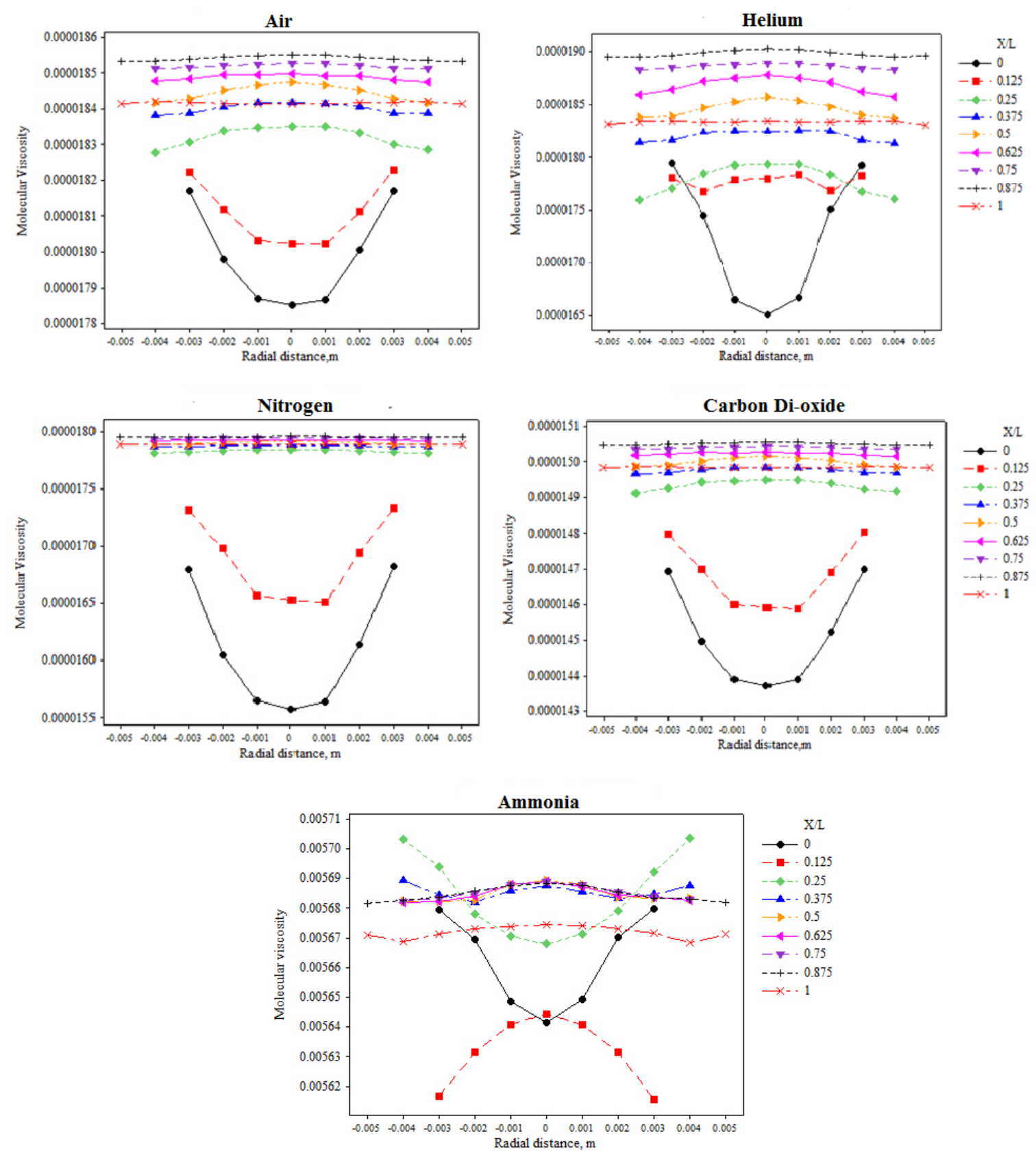

Figure 16. Comparison of radial distribution of viscosity 


\subsection{Turbulence Intensity Distribution}

The turbulence intensity is the ratio of the root-mean-square of the velocity fluctuations to the mean flow velocity. A turbulence intensity of $1 \%$ or less is low and turbulence intensities greater than $10 \%$ are high.

Figure 17 shows the radial distribution of turbulence intensity for all gases. The turbulence intensity for $\mathrm{He}$ and $\mathrm{NH}_{3}$ is highest as compared to all other gases, turbulence intensity of $\mathrm{N}_{2}$ is lowest, and turbulence is the result of velocity distribution in the flow field. As discussed earlier the velocities encountered with helium are more, hence the turbulence intensity is more.
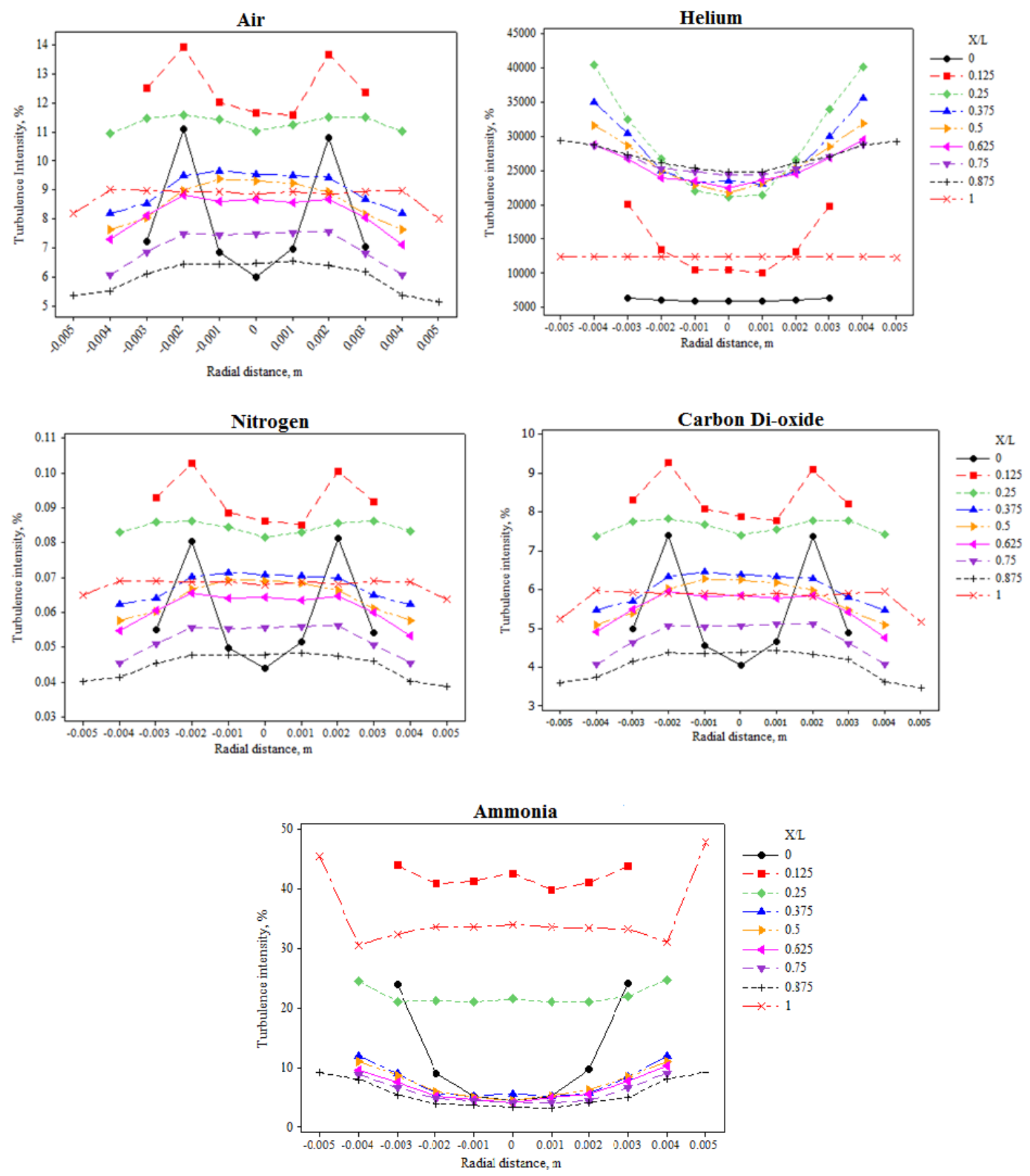

Figure 17. Variations of Turbulence intensity distribution for all gases 
In addition at $\mathrm{X} / \mathrm{L}=0$ and 0.125 the turbulence intensity has gradient that varies with velocity, i.e. it is lowest at the core and there is rise and fall in turbulence intensity. I.e. upto $\mathrm{r}=0.002$ there is rise in intensity and then the intensity drops at periphery. This is the region where the energy transfers from core to periphery. The turbulence intensities decrease from cold end to hot end.

\subsection{Energy Separation for Air}

Figure 18 shows the comparison of cooling effect for air. Comparison of the energy separation (cooling effect) with Skye et al. shows that, results are in good agreement. (Skye, Nellis, \& Klein, 2006) At higher CMF present, numerical work has shown slight increase in energy separation owing to increases mass of cold air. The similar rise is observed for Skye et al. (Skye, Nellis, \& Klein, 2006)

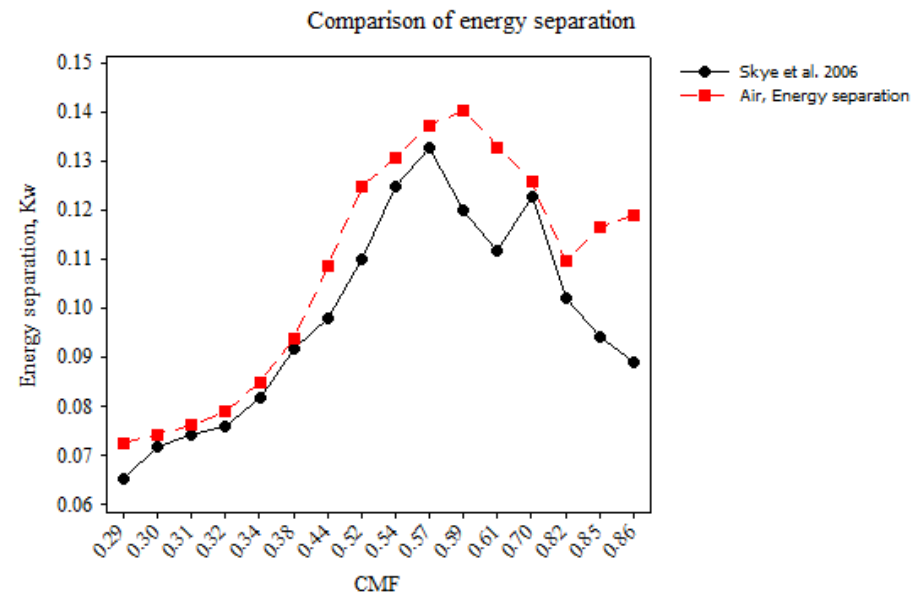

Figure 18. Comparison of results with literature

\subsection{Comparative Studies}

Energy separation for all gases is the temperature difference between hot and cold end. Figure 19 shows the energy separation obtained for different gases. Energy separation for He and $\mathrm{N}_{2}$ is highest than all other gases while, it is minimum for $\mathrm{NH}_{3}$. Energy separation for He is highest because of its low density and higher turbulence created inside the tube. Higher intensity of turbulence is the cause of energy separation for He, while for $\mathrm{N}_{2}$ energy separation is higher because of its high specific heat ratio. Heat transfer rates for all gases are shown in Figure 19. It shows the heat transfers at cold and hot ends. The heat transfer rates for helium and nitrogen are higher. Heat transfer rate for $\mathrm{NH}_{3}$ is higher on hot end.

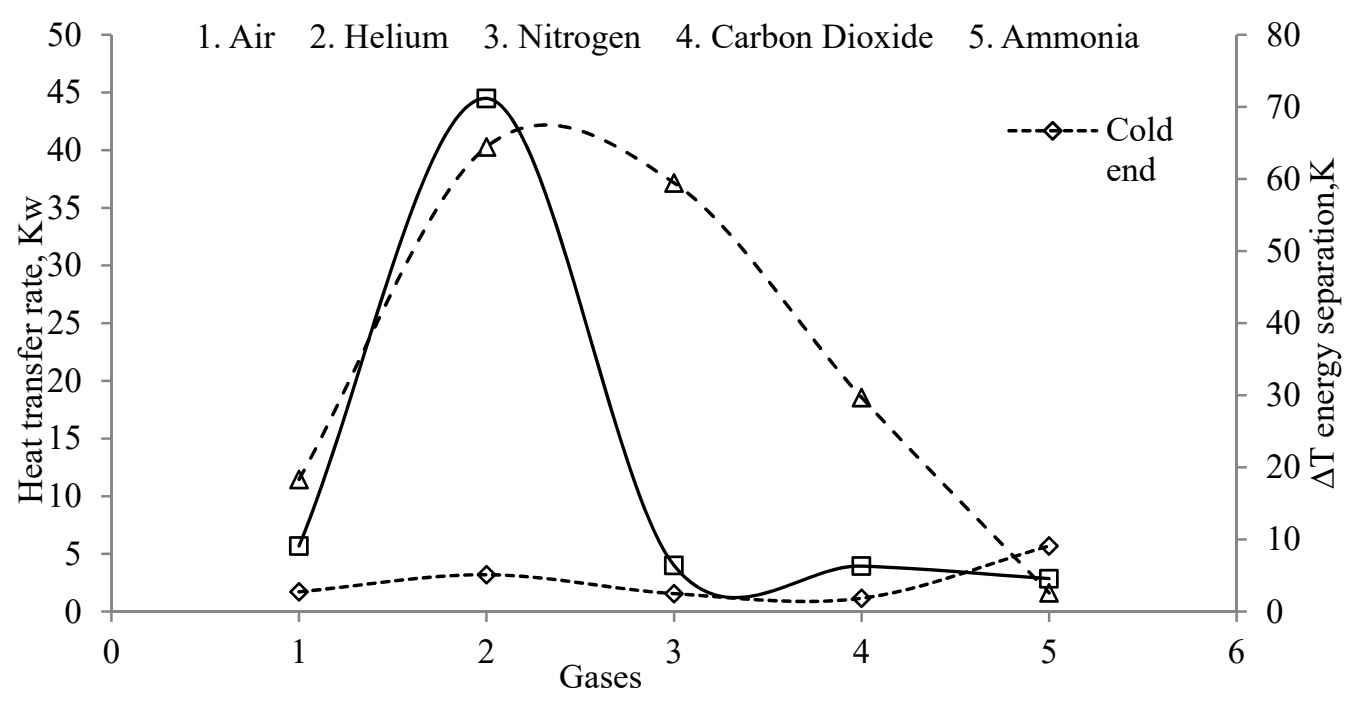

Figure 19. Variation of Temperature separations and Heat transfer for different gases 


\section{Conclusions}

From the numerical analysis of total pressure, total temperature, tangential velocity and density distribution for the mono-atomic, dia-atomic and tri-atomic fluids following conclusions are drawn,

1) Axial pressure distribution shows the axial drop in pressure of all the fluids, the pressures encountered in vortex tube of very small magnitudes.

2) Total pressure decreases along the axis the pressure gradient along the radial direction also decreases. i.e. difference of pressure between peripheral layers to core layers decreases with increasing axial distance from inlet.

3) The fluid properties like kinematic viscosity affect the pressure distribution of gases, the radial pressure distribution profiles for all gases are similar, but the magnitudes are varying.

4) Total temperature at core is less than the total temperature at the periphery and thus the heat transfer theory cannot be justified. The major temperature gradient is observed at $X=0$ i.e. the cold end of the vortex tube and $\mathrm{X}=0.007125$ a section just ahead of the cold end.

5) The highest tangential velocity is noticed at $X=0.07$ which is a zone just close to inlet section. Thus, highest tangential velocity is at inlet and then towards hot and cold end the tangential velocities are lower.

6) Distribution of tangential velocity along the radial plane gives the idea of shearing that may occur because of velocity differences in the fluid.

7) Tangential velocity distribution shows that the core stream gains kinetic energy from the peripheral stream and loses heat to peripheral stream thus heating the peripheral stream and lowering its own temperature. Distributions of tangential velocities appear to be the cause of energy separation.

8) For helium, higher tangential velocities are observed, and because of higher tangential velocities, the energy separation is high for helium.

9) The radial gradient of density at all sections along the axis, indicate the presence of strong centrifugal force. The centrifugal force throws the fluid mass towards the periphery making it denser than the core, similar to the impeller eye of the pump.

10) Density gradient and density distribution increases from $\mathrm{X} / \mathrm{L}=0$ to $\mathrm{X} / \mathrm{L}=0.25$ and at $\mathrm{X} / \mathrm{L}=0.375$ it again drops upto $\mathrm{X} / \mathrm{L}=1$ thus the tube is getting divided axially into low density and high density zones.

11) The distribution of viscosity shows that there exists a axial gradient of viscosity from hot end to cold end. i.e. from $\mathrm{X} / \mathrm{L}=0.5$ to $\mathrm{X} / \mathrm{L}=0.875$ the viscosities are higher, and from $\mathrm{X} / \mathrm{L}=0.5$ to $\mathrm{X} / \mathrm{L}=0.25$ the viscosity is low.

12) Turbulence intensity for $\mathrm{He}$ and $\mathrm{NH}_{3}$ is highest as compared to all other gases, turbulence intensity of $\mathrm{N}_{2}$ is lowest, and turbulence is the result of velocity distribution in the flow field.

13) Energy separation for He is highest because of its low density and higher turbulence created inside the tube while, it is minimum for $\mathrm{NH}_{3}$.

Present work deals with the flow behaviour when mono- atomic, diatomic and tri-atomic gases etc. are used. There is need to establish relationship for stagnation point and the fluid properties. Stagnation point location majorly governs the heating or cooling performance, Hence the effect of CMF and other fluid properties on stagnation point needs to be addressed.

\section{Acknowledgement}

Authors are thankful to Indira College of engineering and Management and Government College of engineering, Karad for providing platform to conduct this work.

\section{References}

Akheshmeh, S., Pourmahmoud, N., \& Sedgi, H. (2008). Numerical Study of the Temperature Separation in the Ranque-Hilsch Vortex Tube. American J. of Engineering and Applied Sciences, 1(3), 181-187.

Aljuwayhel, N. F., Nellis, G. F., \& Klein, S. A. (2005). Parametric and internal study of the vortex tube using a CFD model. International Journal of Refrigeration, 28, 442-450.

Baghdad, M., Ouadha, A., \& Addad, Y. (2012). CFD Modelling and Exergy Analysis of a Vortex Tube Using Co2 as Working Fluid. 10th IIR-Gustav Lorentzen Conference on Natural Working Fluids . Delft, The Netherlands .

Baghdad, M., Ouadha, A., Imine, O., \& Addad, Y. (2011). Numerical study of energy separation in a vortex tube with different RANS models. International Jouranl of Thermal Sciences, 50, 2377-2385. https://doi.org/10.1016/j.ijthermalsci.2011.07.011 
Behera, U., Paul, P. J., Dinesh, K., \& Jacob, S. (2008). Numerical investigations on flow behaviour and energy separation in Ranque-Hilsch vortex tube. International Journal of Heat and Mass Transfer, 51, 6077-6089.

Behera, U., Paul, P. J., Kasthurirengan, S., Karunanithi, R., Ram, S. N., Dinesh, K., \& Jacob, S. (2005). CFD analysis and experimental investigations towards optimizing the parameters of Ranque-Hilsch vortex tube. International Journal of Heat and Mass Transfer, 48, 1961-1973. https://doi.org/10.1016/j.ijheatmasstransfer.2004.12.046

Bezprozvannykh, V., \& Mottl, H. (1999). The Ranque-Hilsch Effect: CFD Modeling. Canada: DYCOR Technologies.

Bovand, M., Valipour, M. S., Dincer, K., \& Tamayol, A. (2014). Numerical analysis of the curvature effects on RanqueeHilsch vortex tube refrigerators. Applied Thermal Engineering, 65, 176-183. http://dx.doi.org/10.1016/j.applthermaleng.2013.11.045

Brun, M. E. (1933). A propose de la communication by Ranque. France: Journal de Physique et le radium.

Deissler, R. G., \& Perlmutter, M. (1960). Analysis of the Flow and Energy Separation in a Turbulent Vortex. International Journal of Heat Mass Transfer, 1, 1783-191.

Devade, K. D., \& Pise, A. T. (2014). Effect of cold orifice diameter and geometry of hot end valves on performance of converging type Ranque Hilsch vortex tube. Energy Procedia, 642-653. https://doi.org/10.1016/j.egypro.2014.07.306

Dutta, T., Sinhamahapatra, K. P., \& Bandyopdhyay, S. S. (2010). Comparison of different turbulence models in predicting the temperature separation in a Ranque-Hilsch vortex tube. International Journal of Refrigeration, 33, 783-792. https://doi.org/10.1016/j.ijrefrig.2009.12.014

Dutta, T., Sinhamahapatra, K., \& Bandopadhyay, S. S. (2011). Numerical investigation of gas species and energy separation in the Ranque -Hilsch vortex tube using real gas model. International Journal of Refrigeration. https://doi.org/10.1016/j.ijrefrig.2011.06.004

Eiamsa-ard, S., \& Promvonge, P. (2006). Numerical prediction of vortex flow and thermal separation in a subsonic vortex tube. Journal of Zhejiang University SCIENCE A, 7(8), 1406-1415.

Farouk, T., \& Farouk, B. (2007). Large eddy simulations of the flow field and temperature separation in the RanqueHilsch vortex tube. International Journal of Heat and Mass Transfer, 50, 4724-4735.

Farouk, T., Farouk, B., \& Gutsol, A. (2009). Simulation of gas species and temperature separation in the counter-flow Ranque-Hilsch vortex tube using the Large Eddy Simulation technique. International Journal of Heat and Mass Transfer, 52, 3320-3333. https://doi.org/10.1016/j.ijheatmasstransfer.2009.01.016

Gutsol, A. F. (1997). The Ranque Effect. Uspekhi Fizicheskikh Nauk, Russian Academy of Sciences, 40(6), 639-658.

Hilsch, R. (1947). The Use of the Expansion of Gases in a Centrifugal Field as Cooling Process. The Review of Scientific Instruments, 18(2), 108-113.

Im, S. Y., \& Yu, S. S. (2012). Effects of geometric parameters on the separated air flow temperature of a vortex tube for design optimization. Energy, 37, 154-160. https://doi.org/10.1016/j.energy.2011.09.008

Kazantseva, O. V., Piralishvili, S. A., \& Fuzeeva, A. A. (2005). Numerical Simulation of Swirling Flows in Vortex Tubes. High Temperature, 43(4), 608-613. https://doi.org/0018-151X/05/4304-0608

Khazaei, H., Teymourtash, A. R., \& Jafarian, M. M. (2012). Effects of gas properties and geometrical parameters on performance of a vortex tube. Scientia Iranica, 19(3), 1-9.

Linderstrom-Lang, C. U. (1971). The three-dimensional distributions of tangentail velocity and total temperature in vortex tubes. Journal of Fluid Mechanics, 45(1), 161-187.

Pinar, A. M., Uluer, O., \& Kirmaci, V. (2009). Optimization of counter flow Ranque-Hilsch vortex tube performance using Taguchi method. International Journal of Refrigeration, 32, 1487-1494.

Polat, K., \& Kirmaci, V. (2011). Application of the output dependent feature scaling in modeling and prediction of performance of counter flow vortex tube having various nozzles numbers at different inlet pressures of air, oxygen, nitrogen and argon. International Journal of Refrigeration, 34(6), 1387-1397.

Pourmahmoud, N., Hassanzadeh, A., \& Moutaby, O. (2012). Numerical analysis of the effect of helical nozzles gap on the cooling capacity of RanqueeHilsch vortex tube. International Journal of Refrigeration, 35, 1473-1484. https://doi.org/10.1016/j.ijrefrig.2012.03.019

Rafiee, E. S., \& Rahimi, M. (2013). Experimental study and three-dimensional (3D) computational fluid dynamics (CFD) analysis on the effect of the convergence ratio,pressure inlet and number of nozzle intake on vortex tube 
performanceeValidation and CFD optimization. Energy, 63, 195-204. http://dx.doi.org/10.1016/j.energy. 013.09 .060

Ranque, G. J. (1933). Experiences sur la detente giratoire avec productions simultanees d'un echappementd'air chaud et dun echappement d'air froid,. Journal of Physics Radium, 4(7), 1128.

Redlich, O., \& Kwong, J. N. (1949). On the thermodynamics of solutions: An equation of state: Fugacities of gaseous solutions. Chemical Revisions, 44, 233-244.

Scheper, G. W. (1951). The Vortex Tube- Internal Flow Data and Heat Transfer Theory. Journal of the ASRE, 985990.

Secchiaroli, A., Ricci, R., Montelpare, S., \& D'Alessandro, V. (2009). Numerical simulation of turbulent flow in a Ranque-Hilsch vortex tube. International Journal of Heat and Mass Transfer, 52, 5496-5511. https://doi.org/10.1016/j.ijheatmasstransfer.2009.05.031

Shamsoddini, R., \& Nezhad, A. H. (2010). Numerical analysis of the effects of nozzles number on the flow and power of cooling of a vortex tube. International Journal of Refrigeration, 33, 774-782. https://doi.org/10.1016/j.ijrefrig. 009.12 .029

Skye, H. M., Nellis, G. F., \& Klein, S. A. (2006). Comparison of CFD analysis to empirical data in a commercial vortex tube. International Journal of Refrigeration, 29, 71-80.

Sutherland, W. (1893). The viscosity of gases and molecular force. Philosophical Magazine, 5(36), 507-531.

Thakare, H. R., \& Parekh, A. D. (2014). CFD analysis of energy separation of vortex tube employing different gases, turbulence models and discretisation schemes. International Journal of Heat and Mass Transfer, 78, 360-370. http://dx.doi.org/10.1016/j.ijheatmasstransfer.2014.06.083

Westley, R. (1954). A Bibliography and Survey of Vortex Tubes. Kanaalstraat 10 - DELFT: TECHNISCHE HOGESCHOOL, Department of Aerodynamics.

Xue, Y., Arzomandi, M., \& Kelso, R. (2011). Visualization of the flow structure in a vortex tube. Experimental Thermal and Fluid Science, 1-23. https://doi.org/10.1016/j.expthermflusci.2011.07.001

\section{Copyrights}

Copyright for this article is retained by the author(s), with first publication rights granted to the journal.

This is an open-access article distributed under the terms and conditions of the Creative Commons Attribution license (http://creativecommons.org/licenses/by/4.0/). 